\title{
Numerical Analysis of the Effluent Dispersion in Rivers with Different Longitudinal Diffusion Coefficients
}

\author{
A. G. S. L. Ritta ${ }^{1 \dagger}$, T. R. Almeida ${ }^{2}$ J. T. A. Chacaltana ${ }^{3}$ and R. M. Moreira ${ }^{1}$ \\ ${ }^{1}$ Fluminense Federal University, Niterói, Rio de Janeiro, 24210-240, Brazil \\ ${ }^{2}$ Federal University of Rio Grande, Rio Grande, Rio Grande do Sul, 96203-900, Brazil \\ ${ }^{3}$ Federal University of Espírito Santo, Vitória, Espirito Santo, 29075-910, Brazil
}

$\dagger$ Corresponding Author Email: almirgslritta@gmail.com

(Received September 30, 2019; accepted January 13, 2020)

\begin{abstract}
The knowledge of pollutants dispersion in water bodies is a matter of concern in water quality control, especially when a new industrial development is installed e.g. near riverbanks. To predict pollutants dispersion in rivers, analytical, experimental and in-situ measurement can be performed. However, analytical estimation usually results in low accuracy, while experimental or in situ measurement are quite expensive in time and equipment. Hence, Computational Fluid Dynamics (CFD) approach is other alternative that can be used to obtain simple and accurate results for mass transport in rivers. In other words, it is a good alternative to analyse pollutants dispersion. As it is known, longitudinal diffusion coefficient $(E)$ has strong influence on pollutants spreading into the water body. Therefore, the purpose of this paper is to analyse the effects of $\mathrm{E}$ on the mass transport of a conservative pollutant in rivers and channels via CFD. Contaminant dispersion is carried out by a scalar advection-diffusion transport equation that represents the conservation of mass. The velocity and pressure fields are calculated, considering an incompressible fluid, through the Navier-Stokes and the continuity equations. Numerical and analytical results, for one-dimensional (1D) flow, are compared in order to obtain the concentration field, over time and space, using different parametric equations. The concentration field showed significant differences of concentration peak and arrival time of the plume depending on the equation used to predict E. Numerical results, for two-dimensional (2D) flow, are compared with the experimental data from Modenesi et al. (2004). Such analyses are necessary to establish an appropriate correlation between simulated and real channel. The use of different parametric equations for the $E$ in a $2 \mathrm{D}$ channel reveals significant differences of concentration peak and arrival time of the plume. As expected, the numerical results of the transport of pollutants show the dependence on the parameterization of the longitudinal dispersion coefficient. The one that best represents the distribution of pollutants is that proposed by Kashfipour \& Falconer.
\end{abstract}

Keywords: Computational Fluid Dynamics (CFD); Longitudinal diffusion coefficient; Parametric equations.

\section{NOMENCLATURE}

$\begin{array}{ll}\mathrm{B} & \begin{array}{l}\text { average width } \\ \text { concentration }\end{array} \\ \mathrm{C}_{0} & \begin{array}{l}\text { initial concentration } \\ \text { longitudinal diffusion coefficient } \\ \mathrm{E}\end{array} \\ \mathrm{E}_{\mathrm{D}} & \begin{array}{l}\text { coefficient calculated by Devens et al. } \\ (2006)\end{array} \\ \mathrm{E}_{\mathrm{F}} & \begin{array}{l}\text { coefficient calculated by Fischer et al. } \\ (1979)\end{array} \\ \mathrm{EKF}_{\mathrm{K}} & \begin{array}{l}\text { coefficient calculated by Kashfipour \& } \\ \text { Falconer }(2002)\end{array} \\ \mathrm{E}_{\mathrm{t}} & \begin{array}{l}\text { coefficient equal eddy viscosity } \\ \text { average depth } \\ \mathrm{K}_{\mathrm{D}}\end{array} \\ \mathrm{K} & \begin{array}{l}\text { coefficient calculated by Devens et al. } \\ \text { (2006) }\end{array} \\ \mathrm{K}_{\mathrm{F}} & \begin{array}{l}\text { coefficient calculated by Fischer et al. } \\ (1979)\end{array} \\ \mathrm{K}_{\mathrm{KF}} & \text { coefficient calculated by Kashfipour \& }\end{array}$

$\begin{array}{ll} & \text { Falconer (2002) } \\ \mathrm{P} & \text { modified pressure } \\ S & \text { slope } \\ S_{c} & \text { Schmidt number } \\ t & \text { time } \\ t_{0} & \text { initial time } \\ U & \text { average velocity } \\ \vec{u} & \text { velocity field } \\ u^{*} & \text { friction velocity } \\ v & \text { velocity of the river } \\ x & \text { length } \\ & \\ \delta(x) & \text { Dirac function } \\ \mu & \text { viscosity } \\ v & \text { turbulent kinematic viscosity } \\ \rho & \text { density }\end{array}$




\section{INTRODUCTION}

Water resources have always been important to humanity. Since ancient times, civilization has been developing its society near places that offer access to water sources. Nowadays, researchers are looking for methods to preserfve or minimize the water pollution implication of excessive water usage that has already been caused by humans. Advanced knowledge of fluid dynamics and the dispersion of pollutants in rivers became important to overcome future endeavours related to river pollution. The necessity of knowledge in predicting, monitoring and controlling pollutant transport in open channels has encouraged many studies related to dispersion in stream flows. (Dimian et al. 2013; Pannone et al. 2014 and Pannone et al. 2018).

In general, a partial differential equation (PDE) for movement and mass transport has an analytical solution when it is linearized. Even whether it is simplified, it can be used as boundary condition and/or geometry simplification. The analytical solution provides important information about the physical problem and it can be useful to identify important parameters to be take into account during CFD analyses. Another way to obtain a solution from non-linear PDE is through numerical modelling. As general rule, numerical results are compared with insitu measurements, experimental tests or analytical data to validate their veracity. Validation through insitu measurements is the best approach to prove that the numerical solution is representing the reality, because it is the most realistic procedure to obtain data from river fluid dynamics (Modenesi et al. 2004). On the other hand, in-situ measurements are quite expensive and they are usually prohibited for safety reasons or due to non-authorization from environmental agencies to access the area. An alternative to obtain reliable data is through controlled laboratory experiments. Thus, mathematical modelling can be improved to realistically represent the problem (Launder and Spalding 1974).

The longitudinal diffusion coefficient $(E)$ is an important parameter in open channel flow. It is directly related to the dispersion of the pollutant along the water channel. Therefore, understanding its role is essential for the numerical solution (Zhang 2011). There are many parametric equations able to predict $E$. These equations were proposed to be used as a way to predict the value of $E$ using the river and/or flow characteristics without the necessity for laboratory or in-situ measurements (Taylor 1954).

In this paper the hydrodynamics and the kinetics of the effluent discharge are simulated using COMSOL Multiphysics ${ }^{\circledR} 4.4$, which is a solver and simulation software/package for different physics and engineering applications, especially coupled phenomena (COMSOL Multiphysics Reference Manual 2013). The measurement of concentration and arrival times of the plume are analysed and compared with the classical linear transport model for instantaneous and continuous discharges.

\section{COMPUTATIONAL PROCEDURE}

The non-linear transport equation for concentration of a given conservative effluent is given by:

$\frac{\partial C}{\partial t}+\vec{u} \cdot \nabla C=E \nabla^{2} C$

where $C, \vec{u}$, and $E$ represent, respectively, the concentration field $\left(\mathrm{mol} / \mathrm{m}^{3}\right)$, the river velocity field $(\mathrm{m} / \mathrm{s})$ and the longitudinal diffusion coefficient $\left(\mathrm{m}^{2} / \mathrm{s}\right)$.

The equations for one-dimensional flow and semiempirical model for concentration of a given pollutant, at time $t$ and space $x$ can be linearized. For a continuous pollutant load with constant inlet velocity, the differential Eq. (1) has the following analytical solution (Tucci 1998).

$C=\frac{C_{0}}{2}\left\{\operatorname{erf}\left[\frac{x+v\left(t-t_{0}\right)}{\sqrt{4 E\left(t-t_{0}\right)}}\right]-\operatorname{erf}\left[\frac{x-v t}{\sqrt{4 E t}}\right]\right\}$

where $\mathrm{C}_{0}$ is the initial concentration considering a homogeneous mixing. According to Devens et al. (2006), for an instantaneous discharge with initial concentration $\mathrm{C}_{0}$, the differential Eq. (1) is linearized using Eq. (5) and it has the following analytical solution Eq. (3);

$C(x, t)=\frac{C_{0}}{\sqrt{4 \pi E t}} e^{-\left(\frac{(x-v t)^{2}}{4 E t}\right)}$

To perform the instantaneous discharge simulation, the concentration of the plume follows Eq. (4):

$C=C_{0} e^{-\left(\frac{t}{3}\right)^{2.1}}$

Note that the 1D linear solution given by Eq. (3) was deducted using the Eq. (5), instead of the Eq. (4), because there is not a possibility to implement the Dirac function in COMSOL. Consequently, an exponential equation (Eq. 4) was applied to simulate a pulse discharge.

$C=C_{0} \delta(x)$

The unknown river velocity field $\vec{u}$ can be determined by assuming an incompressible fluid with the conservation of both mass and momentum respectively given by the Eqs. (6) and (7).

$\nabla \cdot \vec{u}=0$

$\rho \frac{D \vec{u}}{D t}=-\nabla P+\mu \nabla^{2} \vec{u}$

where $\rho, \mu$ and $P$ are, respectively, the density, the dynamic viscosity of water and the modified pressure. A RANS (Reynolds Averaged NavierStokes) turbulence model is introduced based on the $k-\varepsilon$ formulation (Launder and Spalding 1974). Neumann and Dirichlet conditions are applied to the channel's boundaries i.e. impermeability and no-slip boundary conditions are imposed to its surface. COMSOL Multiphysics release 4.4 with the CFD module was used to simulate $1 \mathrm{D}$ and $2 \mathrm{D}$ problems. This software uses the finite element method in combination with adaptive meshing and error control using variety of numerical solvers. It is a commercial CFD tool, which can be used to analyse multiphysics phenomena solving the governing partial differential 
equations with its proper boundary conditions (COMSOL Multiphysics Reference Manual 2013). The simplest way to address the $1 \mathrm{D}$ problem is a single-line mesh. In 2D problem, the triangular element mesh is commonly used with refinement in specific spots to capture particular perturbation (see Fig. 8) (Reddy 2006).

The computational model used is an Eulerian approach coupled with $\kappa-\varepsilon$ turbulence model to solve the turbulence in the system. The boundary conditions applied in the simulation are velocity inlet for river and pollutant inlet, atmospheric pressure outlet for outlet boundary. The problem was divided in two steps. At the first step, the velocity and pressure fields are calculated using steady state approach and it stopped when the residue for continuity is equal to $1 \times 10^{-3}$. The second step, the mass concentration profile, transient approach, is calculated until the residue for continuity is equal to $1 \times 10^{-6}$.

In Table 1, some parametric expressions for the longitudinal dispersion coefficient are shown. Where $E_{F}, E_{K F}$ and $E_{D}$ are, respectively, the dispersion coefficient proposed by Fischer et al. (1979), Kashfipour \& Falconer (2002) and Devens et al. (2006) (Ritta et al. 2016; Soares et al. 2013).

Table 1 Empirical models used to predict $\mathbf{E}$ in rivers

\begin{tabular}{|c|c|}
\hline Parametric equation & Equation \\
\hline$E_{F}=0.011 \frac{U^{2} B^{2}}{H u_{*}}$ & (8) \\
\hline$E_{K F}=10.612 H U \frac{U}{u_{*}}$ & $(9)$ \\
\hline$E_{D}=0.729 \frac{U^{0.774} B^{1.031} S^{0.036}}{H^{0.151}}$ & (10) \\
\hline
\end{tabular}

At the Table 1. $U$ is the average river velocity $(\mathrm{m} / \mathrm{s})$, $B$ is the average width $(\mathrm{m}), \mathrm{H}$ is the average depth (m), $\mathrm{u}^{*}$ is the friction velocity $(\mathrm{m} / \mathrm{s}), \mathrm{S}$ is the slope (dimensionless), (Ritta et al. 2016; Soares et al.2013).

\section{RESULTS AND DISCUSSION}

\subsection{One-Dimensional Analysis}

The line graph (Fig. 1) outlines the trend of the pollutant dispersion along a $1 \mathrm{D}$ channel with $15 \mathrm{~km}$ length and $\mathrm{E}$ equal to $11.57 \mathrm{~m}^{2} / \mathrm{s}$. Analytical and numerical results are compared for a continuous (a) and instantaneous (b) discharge. At the first glance, Fig. 1.a demonstrates a good agreement between the analytical and numerical results, both lines present a plateau, and suddenly they sharply dropped from $1000 \mathrm{~mol} / \mathrm{m}^{3}$ to almost zero. On the other hand, the curves in Fig 1.b present a descending trend meanwhile the numerical profile (dotted line) goes down slightly less than the analytical profile. That difference is attributed to the particular initial conditions used to deduct Eq. (3), because the Dirac function (Eq. 5) can reproduce an instantaneous discharge more realistically than an exponential equation (Eq. 4).
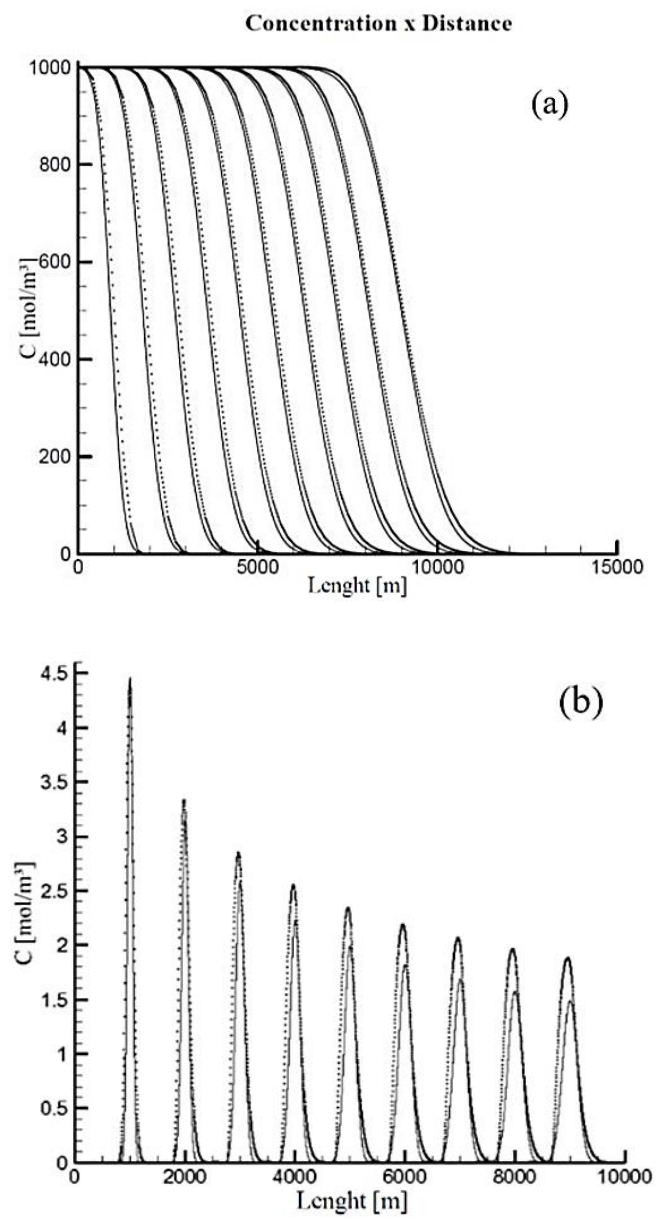

Fig. 1. Analytical (solid line) versus numerical (dotted line) results for a) continuous discharge and $b$ ) instantaneous discharge over $10^{4} \mathrm{~s}$ $\left(\mathrm{C}_{0}=103 \mathrm{~mol} / \mathrm{m}^{3} ; \mathrm{U}=1.0 \mathrm{~m} / \mathrm{s} ; \mathrm{E}=11.57 \mathrm{~m}^{2} / \mathrm{s}\right)$.

\subsection{Two-Dimensional Analysis}

\subsubsection{Verification Case using the Data from} Modenesi

As already was mentioned, there are many parametric equations able to predict the value of $E$ only using values from the river fluid dynamics and/or from the river layout such as average velocity, average width, average depth, friction velocity and slop. In this article, three equations were chosen to demonstrate how $E$ affects the results. Fischer et al. (1979) proposed the first parametric equation (Eq. (8), the second one was deducted by Kashfipour \& Falconer (2002) (Eq. (9)) and Devens et al. (2006) developed the third one Eq. (10).

The experiment carried out by Modenesi et al. (2004) is used to validate the numerical results. This article was chosen because the channel studied has some similarities with Caceribu River, a rectified channel with a side effluent discharge. In Fig. 2, four horizontal parallel lines were design at 3,11,22 and 


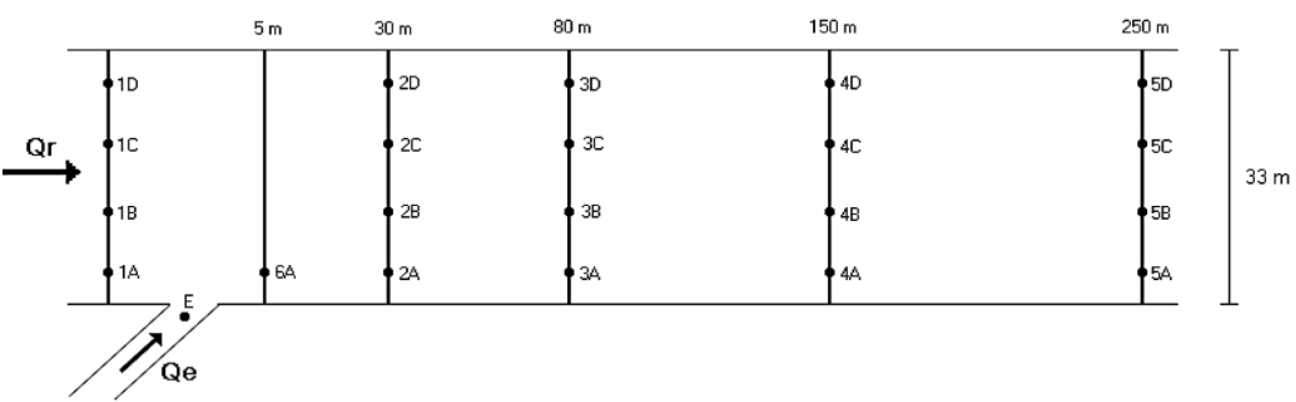

Fig. 2. Schematic representation of the sampling points in the channel examined by Modenesi et al, (2004).
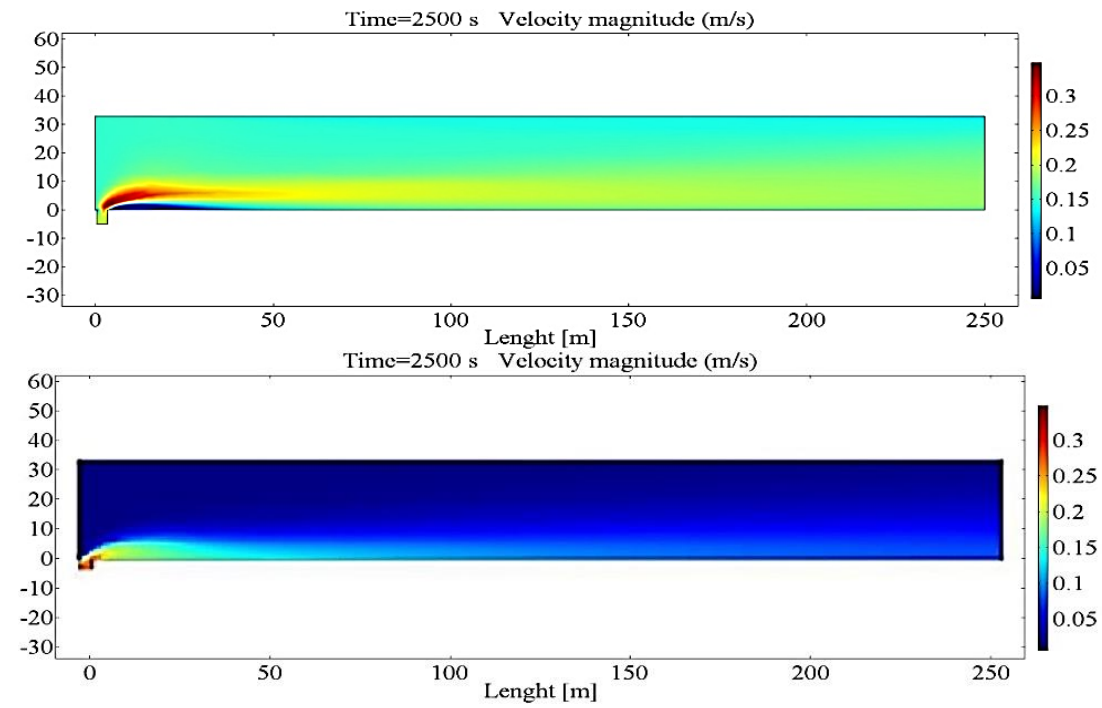

Fig. 3. Zoom in the channel to show the numerical results along the 2D scheme. a) Velocity field (m/s), b) the steady state concentration field $\left(\mathrm{mol} / \mathrm{m}^{3}\right)$.

30 meters away from the effluent river margin, which correspond, respectively, to line $\mathrm{A}, \mathrm{B} \mathrm{C}$ and $\mathrm{D}$. Figure 3 illustrates the velocity $(\mathrm{m} / \mathrm{s})$ and concentrations $\left(\mathrm{mol} / \mathrm{m}^{3}\right)$ of the pollutant. The values of the parameters applied in this simulation are listed in Table 2. The numerical results are compared with experimental data from Modenesi et al. (2004) and they are illustrated in Figs. 4, 5, 6 and 7. In order to verify the numerical solutions, some simulations are carried out replacing the value of $\mathrm{E}$ by the parametric equations given by Eqs. (8), (9) and (10).

Table 2 Parameters used in the simulations

\begin{tabular}{|c|c|c|}
\hline Parameter & Value & Unit \\
\hline Averaged channel velocity & 0.10 & $\mathrm{~m} / \mathrm{s}$ \\
\hline Averaged effluent velocity & 0.12 & $\mathrm{~m} / \mathrm{s}$ \\
\hline Effluent inlet concentration & 1.00 & $\mathrm{~mol} / \mathrm{m}^{3}$ \\
\hline Fluid viscosity & $1.0 \times 10^{-3}$ & $\mathrm{~Pa} . \mathrm{s}$ \\
\hline $\begin{array}{c}\text { Longitudinal diffusion } \\
\text { coefficient }\end{array}$ & 0.02 & $\mathrm{~m}^{2} / \mathrm{s}$ \\
\hline Fluid density & 1000 & $\mathrm{~kg} / \mathrm{m}^{3}$ \\
\hline
\end{tabular}

Figure 4 displays the results from longitudinal line A. The CFD results obtained with the parametric equations show good agreement with the experimental data from Modenesi et al. (2004).
However, for E equal to $0.02 \mathrm{~m} / \mathrm{s}$, the concentration profile from numerical analysis is higher than the concentration profile from experimental data.

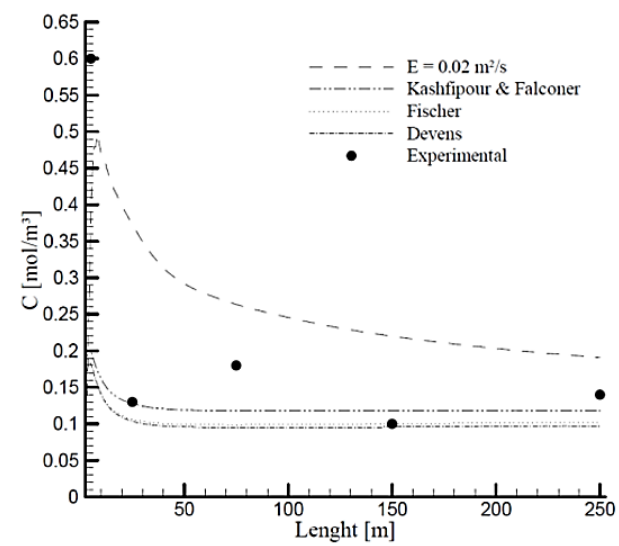

Fig. 4. Profile of chloride concentration obtained numerically (dotted lines) and experimental results (points) from Modenesi et al. (2004) for the longitudinal line of $3 \mathrm{~m}$.

As might be seen in Fig. 5, results from longitudinal line $\mathrm{B}$, the method proposed by Kashfipour \& Falconer demonstrates practically the same pattern 
as the experimental data. While, Devens and Fischer present a similar behaviour, the concentration profile obtained is under the values predicted by experimental data. When E equal to $0.02 \mathrm{~m}^{2} / \mathrm{s}$, the curve does not show similarities with experimental and numerical results.

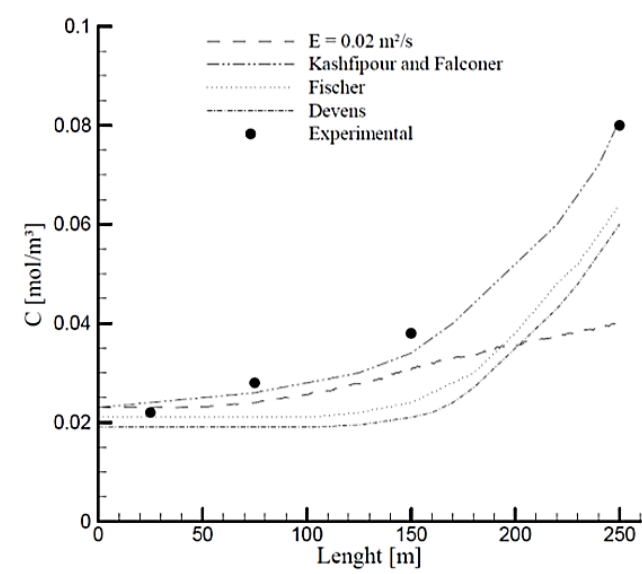

Fig. 5. Profile of chloride concentration obtained numerically (dotted lines) and experimental results (points) from Modenesi et al. (2004) for the longitudinal line of $11 \mathrm{~m}$.

According to the Fig. 6, results from longitudinal line $\mathrm{C}$, which is outside the mixing zone. The numerical curves plateaued after 40 meters. However, their behaviour are not identical with experimental results. The curve for E equal to $0.02 \mathrm{~m}^{2} / \mathrm{s}$ demonstrates an analogue tendency with the experimental data; the only exception is the concentration measured at $250 \mathrm{~m}$ by Modenesi et al. (2004). The measured value is presenting an upward trend, which is not observed numerically.

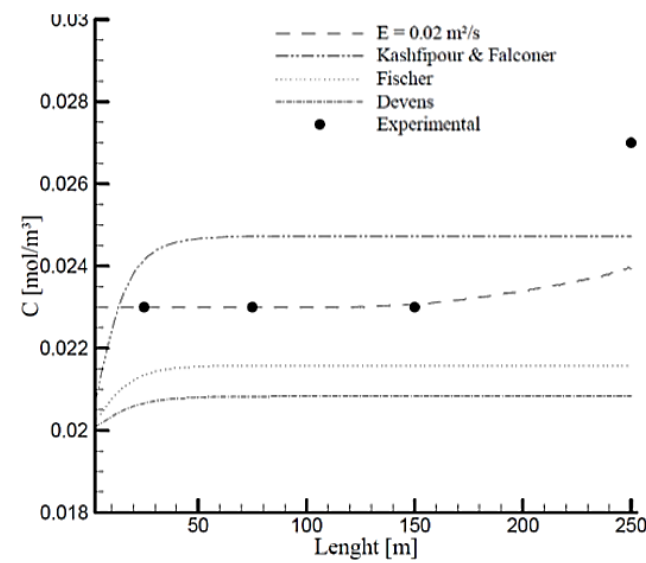

Fig. 6. Profile of chloride concentration obtained numerically (dotted lines) and experimental results (points) from Modenesi et al. (2004) for the longitudinal line of $22 \mathrm{~m}$.

It is interesting to note in Fig 7, results from longitudinal line $\mathrm{D}$, that the numerical outcomes showed good results. Due to the zoom given on the $y$-axis, it appears that the experimental data are discrepant, but the difference between maximum and minimum is less than 0.009 units.

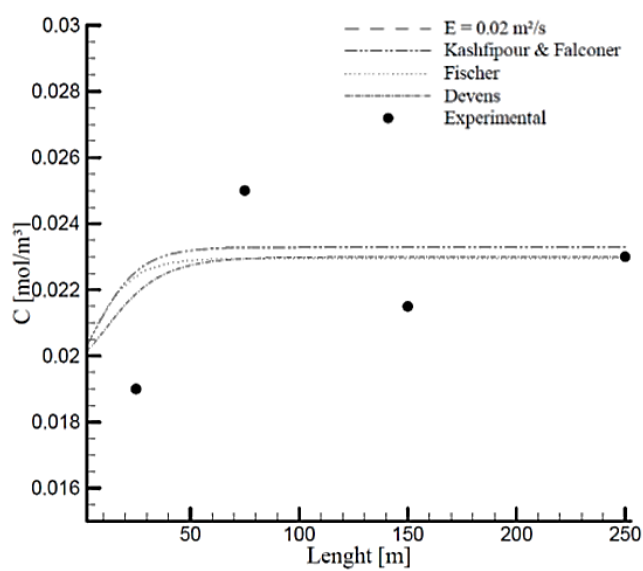

Fig. 7. Profile of chloride concentration obtained numerically (dotted lines) and experimental results (points) from Modenesi et al. (2004) for the longitudinal line of $30 \mathrm{~m}$.

In summary, the parametric equations proposed by different authors and deducted under specific channel's conditions are able to predict the concentration profile. Categorically speaking, the Kashfipour \& Falconer (2002) generates curves with higher concentration values than the other numerical curves. Meanwhile, Devens et al. (2006) and Fischer et al. (1979) presented a small difference in all cases, the concentration obtained by Fischer et al. (1979) showed a slightly higher value.

\subsubsection{Case study - Caceribu River}

In the present study, field data from Caceribu River were taken from Ritta (2016) (Table 3). These parameters were replaced in Eqs. (8), (9) and (10) to make equations that are only function of river velocity. They are going to analysis whether the longitudinal dispersion coefficient affects the CFD results.

Table 3 Parameters from Caceribu River

\begin{tabular}{|c|c|}
\hline Parameter & Value \\
\hline Length $(\mathrm{km})$ & 15 \\
\hline Averaged width of the channel (m) & 24.3 \\
\hline Averaged depth of the channel (m) & 1.70 \\
\hline Declivity (dimensionless) & 0.04 \\
\hline Friction velocity (m/s) & 0.10 \\
\hline
\end{tabular}

Substituting the values from Table 3 into Eqs. (8), (9) and (10), one finds that, the equations to be applied in the numerical analyses are:

$$
\begin{aligned}
& E_{F}=K_{F} U^{2} \\
& E_{K F}=K_{K F} U^{2} \\
& E_{D}=K_{D} U^{0.774}
\end{aligned}
$$

When Schmidt number is equal to one, the momentum diffusivity (kinematic viscosity) is equal to mass diffusivity (Eq. 14). Therefore, E becomes equal to eddy viscosity (see Eq. (15)).

$S_{c}=\frac{v_{t}}{E}=\frac{\text { viscous diffusion rate }}{\text { mass diffussion rate }}$ 


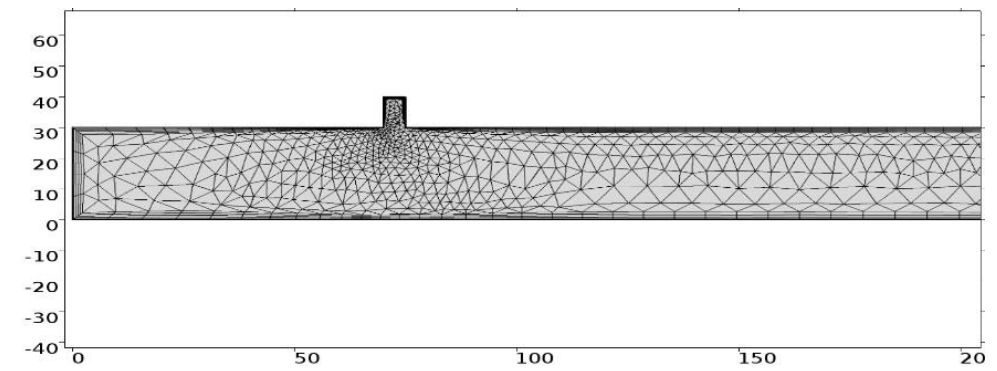

Fig. 8. Computational grid of a part of $15 \mathrm{~km}$ channel for a $2 \mathrm{D}$ analysis.

$E_{t}=v_{t}$

Where $E_{F}, E_{K F}, E_{D}$ and $E_{t}$ are, respectively, the constant value for Fischer et al. (1979), Kashfipour $\&$ Falconer (2002), Devens et al. (2006) and $E=v_{t}$. The constant values are $K_{F}=38.21(\mathrm{~s}), K_{K F}=$ $180.40(\mathrm{~s})$ and $K_{D}=16.07\left(\mathrm{~m}^{1.226} / \mathrm{s}^{0.226}\right)$. These equations were implemented in COMSOL Multiphysics ${ }^{\circledR}$ to compute the effluent dispersion along the river.

The grid used in all simulations is showed in Fig. 8 (the scale is meter). In 2D analysis, a higher refined mesh is used in order to compute the results more accurately. Owing to the necessity to investigate the changes in detail, mesh is more refined near the inlet. A triangular discretization is made with base size of $0.1 \mathrm{~m}$, five boundary layers and a refinement near the pollutant entrance. For convenience, the effluent inlet is positioned at the channel border and it is $70 \mathrm{~m}$ from the beginning of the channel. To analyse the concentration field in this section, a central line is traced. All parameters utilized in this section are indicated in Table 4.

Figure 9 displays the velocity field, which is the same for all simulations, because $\mathrm{E}$ is the only variable different in all cases and it does not affect the velocity field. For continuous discharge, Figures 10 and 11 illustrate a continuous pollutant plume discharged into the river after 500 seconds. According to the Fig. 10, $E$ equal to $0.243 \mathrm{~m}^{2} / \mathrm{s}$, the pollutant spreading is significantly concentrated adjacent to the pollutant inlet. Its plume is barely well diffused along the river and it reaches less than $500 \mathrm{~m}$ after $500 \mathrm{~s}$. On the other hand, when $E$ is equal to $11.57 \mathrm{~m}^{2} / \mathrm{s}$, the plume propagates quickly (see Fig. 11 ). It is fully dispensed and it reaches more than $500 \mathrm{~m}$ after $500 \mathrm{~s}$. It can be clearly observed that the dispersion is proportional to $\mathrm{E}$, as it was expected.

Table 4 Parameters used in the case study Caceribu River

\begin{tabular}{|c|c|c|}
\hline Parameter & Value & Unit \\
\hline Averaged channel velocity & 0.75 & $\mathrm{~m} / \mathrm{s}$ \\
\hline Averaged effluent velocity & 1.00 & $\mathrm{~m} / \mathrm{s}$ \\
\hline Effluent inlet concentration & 1000 & $\mathrm{~mol} / \mathrm{m}^{3}$ \\
\hline Fluid viscosity & $1 \times 10^{-3}$ & $\mathrm{Pa.s}$ \\
\hline Fluid density & 1000 & $\mathrm{~kg} / \mathrm{m}^{3}$ \\
\hline
\end{tabular}

Figure 12 is plotted in order to demonstrate the difference of the concentration profile along the entire channel. The longitudinal diffusion coefficient is the only variable different in both cases. As can be noted in Fig. 12, the greater $E$ is, the higher the steady-state concentration and the travelled distance are.

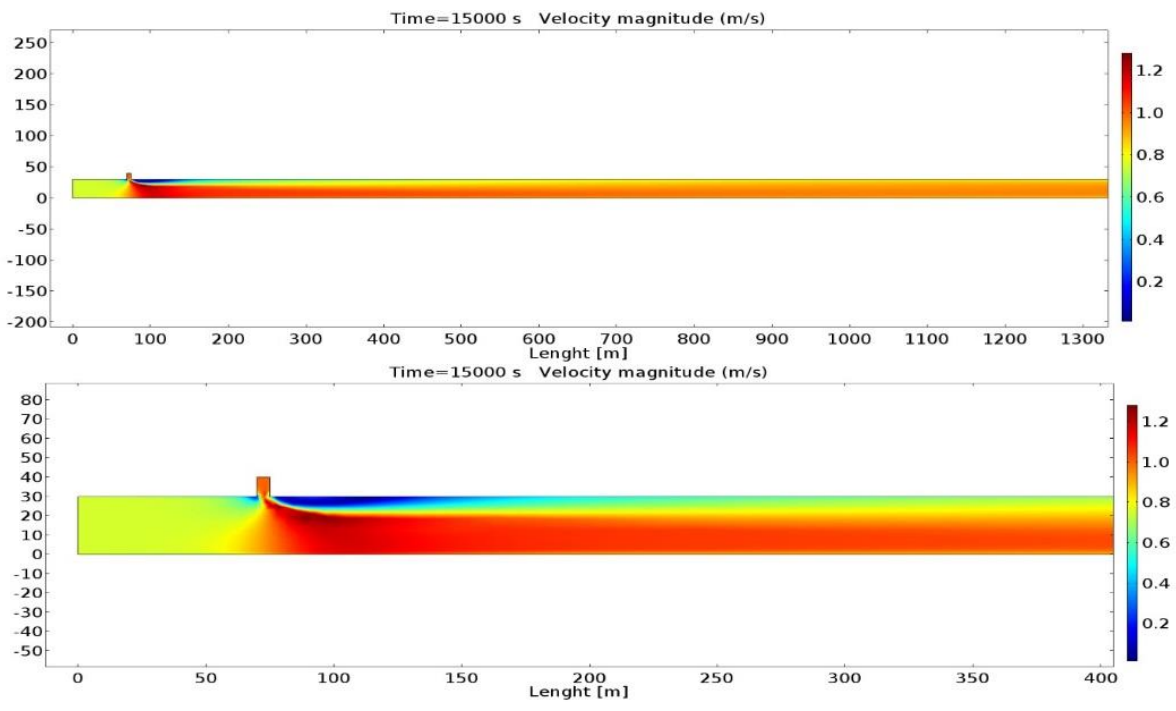

Fig. 9. Velocity field (m/s) a) Zoom showing 1300 meters of channel b) Zoom showing the inlet velocity field. 
A. G. S. L. Ritta et al. / JAFM, Vol. 13, No. 5, pp. 1551-1559, 2020.

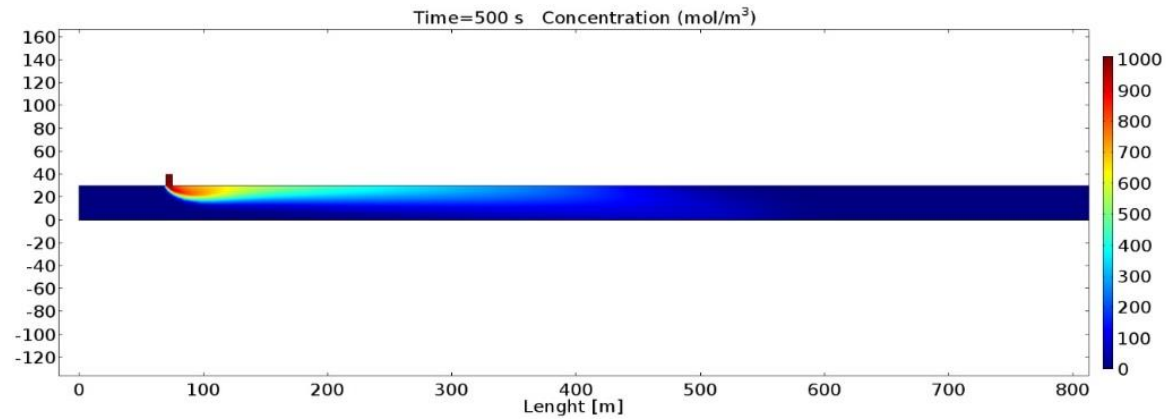

Fig. 10. Numerical analysis with $E=0.243 \mathrm{~m}^{2} / \mathrm{s}$.

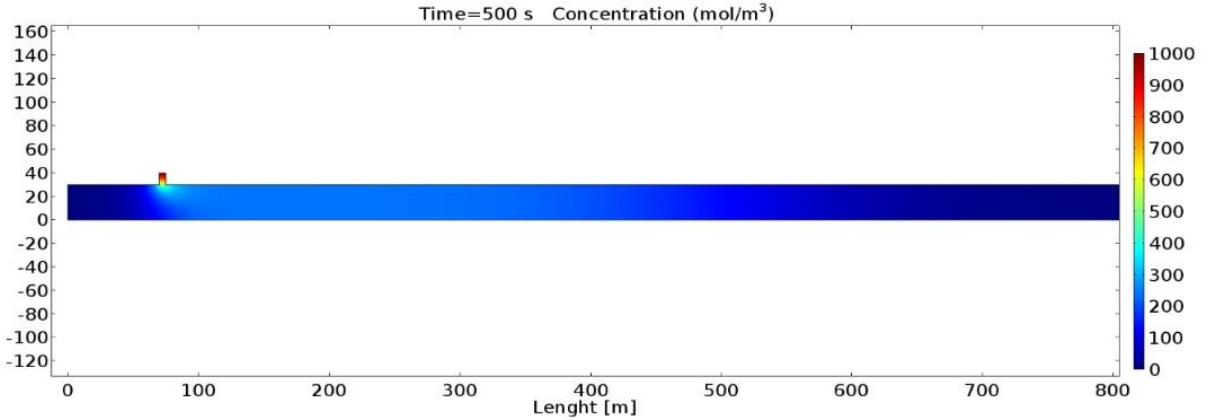

Fig. 11. Numerical analysis with $E=11.57 \mathrm{~m}^{2} / \mathrm{s}$.

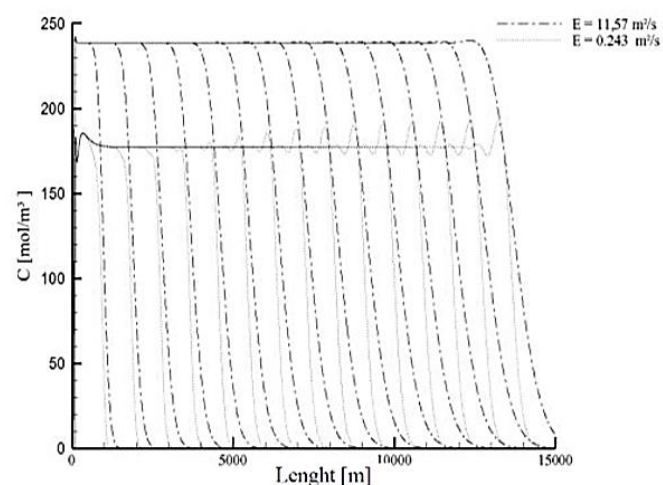

Fig. 12. Concentration of the pollutant along the channel for a continuous discharge over $15,000 \mathrm{~s}$ $(\Delta \mathrm{t}=\mathbf{1 , 0 0 0 s})$.

The numerical results from continuous cases are illustrated in Fig. 13. The maximum concentration value shows a different plateau and it decreases depending of the parametric equation implemented. The Kashfipour \& Falconer curve shows the highest value for steady-state concentration and it has the biggest effluent displacement along the channel. The curves from Fischer and Devens, demonstrate a similar behaviour, but Devens' maximum concentration value is smaller than the Fischer. The stead steady concentration calculated by Fischer is half the value estimated by Kashfipour \& Falconer. Differently, Fig. 13 shows how the turbulence flow affects the dispersion of the effluent near the inlet and the pollutant concentration computed is the smallest value. For an instantaneous discharge, Figs. 14 and 15 present an instantaneous pollutant plume discharged into the river after $500 \mathrm{~s}$. When $\mathrm{E}$ equal to $0.243 \mathrm{~m}^{2} / \mathrm{s}$ is used (Fig. 14), the distribution of the effluent is furtherly concentrate near the inlet wall, it has a non-homogeneous dispersion and it is smaller than in Fig.15. Nevertheless, both plumes do not have a total mixture. In Fig. 15, it is easy to realise that the plume is more homogenous and it slightly diffused.

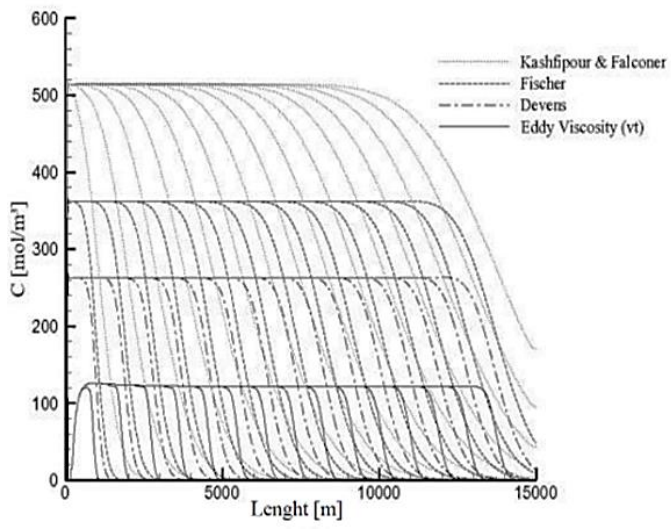

Fig. 13. Concentration of the effluent along the channel. 


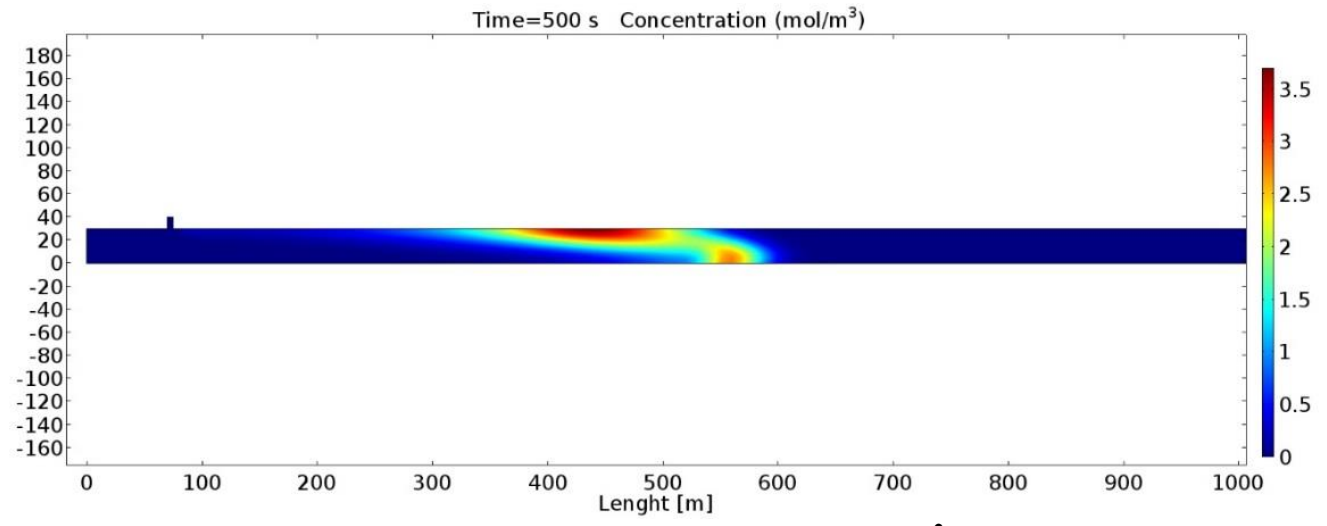

Fig 14. Numerical analysis with $E=0.243 \mathrm{~m}^{2} / \mathrm{s}$.

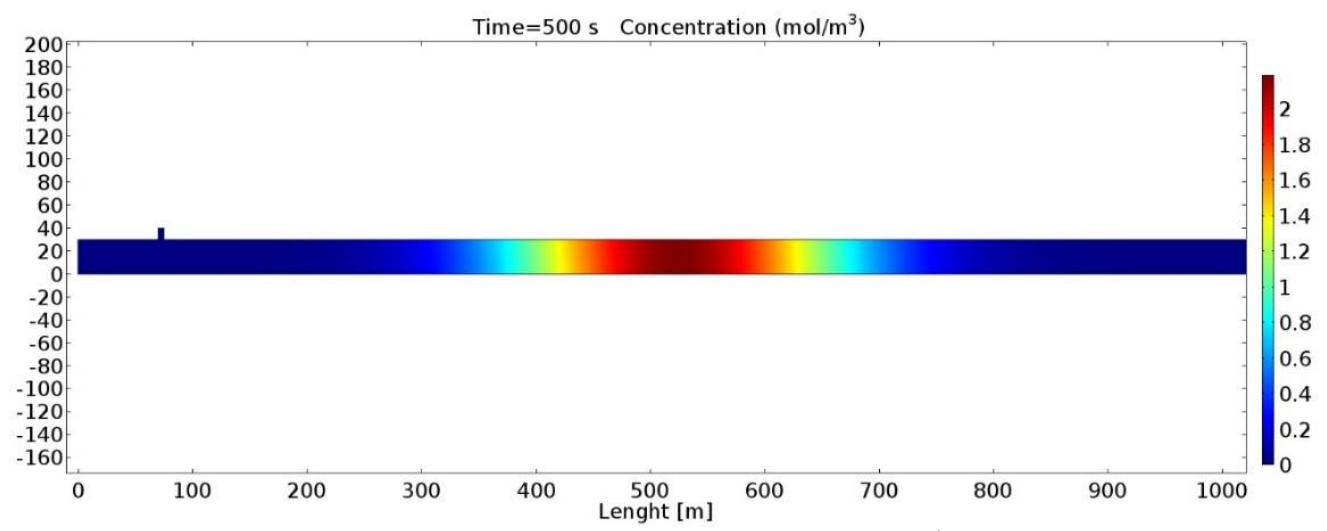

Fig 15. Numerical analysis with $E=11.57 \mathrm{~m}^{2} / \mathrm{s}$.

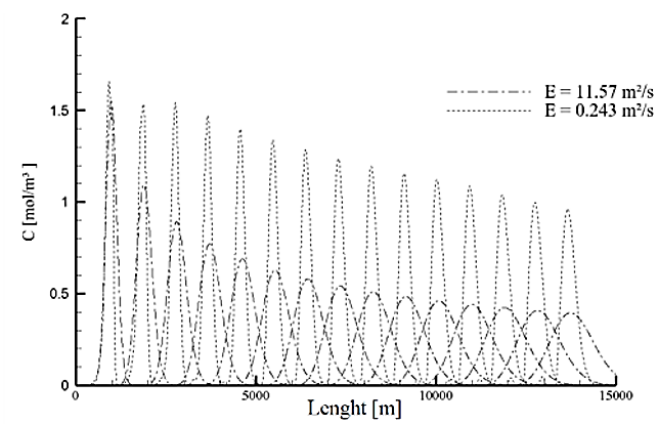

Fig. 16. Concentration of the effluent along the channel.

As previously done, one curve for each equation was plotted to demonstrate the effects of $E$. As might be seen in Fig. 16, both curves keep the same pattern, but with different peaks of concentration. Depending on the value of $E$ the curves become more or less dispersed.

Figure 17 illustrates the pollutant concentration along a 2D channel using Eqs. (8), (9) and (10). The eddy viscosity, from Eq. (15), is also implemented in the software. Each model has its own concentration peak, which decreases with time, when instantaneous discharge occurs. Kashfipour \& Falconer gives the broadest concentration profile whereas the eddy viscosity equation has the smallest diffusion effects. Figure 17 shows significant differences, peak concentration and plume arrival time, depending on the parametric equations employed in the simulation.

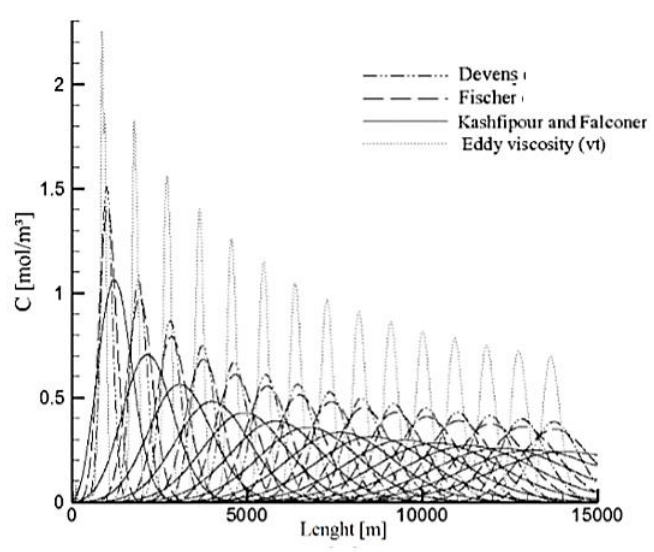

Fig. 17. Concentration of an instantaneous discharge for different diffusion models.

\section{CONCLUSIONS}

To predict pollutant dispersion in rivers, analytical, experimental test and in situ measurement are currently being used. Analytical estimation usually results in low accuracy, while experimental or in situ measurement are quite expensive in time and 
equipment. Because of that, CFD can be a good alternative to analyse pollutant dispersion. Simplified approach, 1D model, can be used to determine the effects of $E$ in river dispersion and to obtain important information about the plume. In 1D analysis, a small difference is found between the profiles, and it is due to the different initial conditions used to deduct the equation. Despite the good agreement between numerical and analytical results, models employed to predict mass transport in a channel need improvement and this necessity is attracting much attention of researchers and engineers. For the 2D analyses, the results for each parametric equation show significant difference between them. As a result, the equation proposed to Kashfipour \& Falconer generated better results. Application of this method depends highly on river's characteristic such as velocity, declivity, length, depth and so on. While there are many simplification applied in this study, the numerical results showed that CFD could be applied to predict pollutant plume accurately. As found in literature, different rivers have different coefficients. Therefore, more systematic studied must be done and any generalization must be carefully examined.

\section{ACKNOWLEDGMENTS}

A. G. S. L. Ritta acknowledges the research grant from CAPES, the Brazilian agency for postgraduate education.

\section{REFERENCES}

COMSOL Multiphysics Reference Manual (2013).

COMSOL Multiphysics ${ }^{\circledR}$ 4.4., COMSOL AB, Stockholm, Sweden.

Devens, J. A., A. R. Barbosa Jr. and G. Q. Silva (2006). Longitudinal dispersion coefficient quantification model of streams. Environmental Sanitary Engineering 11(3), 269-276.

Dimian, M. F. A., A. S. Wadi and F. N. Ibrahim (2013). The effect of added pollutant along a river on the pollutant concentration described by one-dimensional advection diffusion equation. International Journal of Engineering Science and Technology (IJEST) 5(9), 16621671.

Fischer, H. B., E. J. List, R. C. Y. Koh, J. Imberger and N. H. Brooks (1979). Mixing in inland and coastal waters, Academic Press, San Diego,

\section{USA.}

Kashfipour, S. M. and R. A. Falconer (2002). Longitudinal dispersion coefficients in natural channels. Water Research 36, 1596- 1608.

Launder, B. E. and D. B. Spalding (1974). The numerical computation of turbulent flows. Computer Methods in Applied Mechanics and Engineering 3(2), 269-289.

Modenesi, K., L. T. Furlan, E. Tomaz, R. Guirardello and J. R. Núnez (2004). A CFD model for pollutant dispersion in rivers. Brazilian Journal of Chemical Engineering 21(4), 557-568.

Pannone, M. (2014). Predictability of tracer dilution in large open channel flows: Analytical solution for the coefficient of variation of the depthaveraged concentration. Water Resources Research 50(13), 2617-2635.

Pannone, M., D. Mirauda, A. de Vincenzo and B. Molino (2018). Longitudinal dispersion in straight open channels: Anomalous breakthrough curves and first-order analytical solution for the depth-averaged concentration. Water 10(4), 1-15.

Reddy, J. N. (2006). An introduction to the finite element method. Mc-Graw Hill, New York, NY, USA, 3th edition.

Ritta, A. G. S. L, P. S. Estolano, V. A. M. Martins and R. M. Moreira (2016). Numerical modelling of effluent dispersion in rivers with different longitudinal diffusion coefficients. In Proceedings of the 16th Brazilian Congress of Thermal Sciences and Engineering - ENCIT 2016, Vitória, Espírito Santo, Brazil.

Soares, P. A., A. Pinheiro and E. Zucco (2013). Determination of the longitudinal dispersion coefficient in rivers. The Water Management Journal in Latin America 10(2), 27-36.

Taylor, F. R. S. G. (1954). The dispersion of matter in turbulent flow through a pipe. In Proceedings of the Royal Society - A Mathematical, Physical \& Engineering Sciences 223. 446-468.

Tucci, C. E. M. (1998). Hydrological models, Publisher UFRGS, Florianópolis, Santa Catarina, Brazil.

Zhang, W. (2011). A 2-D numerical simulation study on longitudinal solute transport and longitudinal dispersion coefficient. Water Resources Research 47(W07533), 1-13. 